WEBLey, D. M. (1954), J. gen. Micrbiol. 11, 420-425.

\title{
The Morphology of Nocardia opaca Waksman \& Henrici (Proactinomyces opacus Jensen) when Grown on Hydrocarbons, Vegetable Oils, Fatty Acids and Related Substances
}

\author{
BY D. M. WEBLEY \\ Macaulay Institute for Soil Research, Craigiebuckler, Aberdeen
}

SUMMARY: Nocardia opaca Waksman \& Henrici can use certain long chain saturated aliphatic hydrocarbons and many vegetable oils as sole carbon and energy source in presence of simple mineral salts. Long chain saturated aliphatic acids (e.g. myristic, palmitic and stearic) can similarly serve.

The same general morphological development is obtained on all these compounds but the initial mycelial phase is more pronounced on oily substrates (particularly hydrocarbons) than on water soluble or insoluble solid substances. Granules are demonstrable inside the cells. These granules are more intensely stained with fat and polysaccharide reagents than the rest of the cell. Well-defined electron dense bodies are also observed which behave similarly to the 'mitochondria' described by Mudd, Winterscheid, DeLamater \& Henderson (1951) in Mycobacterium thamnopheos under intense electron bombardment.

Webley \& de Kock (1952) showed, by means of the Warburg technique, that the addition of certain long chain saturated aliphatic hydrocarbons, alcohols and acids to washed suspensions of Nocardia opaca grown on a glucose containing medium enhanced oxygen uptake. In the present paper a study has been made of the growth and morphology of this organism with these substances as sole carbon and energy sources. The work was extended to include vegetable oils, some waxes and other related substances.

\section{METHODS}

Organism. Nocardia opaca strain $\mathbf{T}_{16}$ was used throughout (Webley \& de Kock, 1952).

Growth experiments were carried out in 2 oz. screw-capped bottles containing $5 \mathrm{ml}$. medium. A mineral medium of the following composition was used throughout $(\%, \mathrm{w} / \mathrm{v}): \mathrm{NaNO}_{3}, 0.2 ; \mathrm{NaCl}, 0.02 ; \mathrm{MgSO}_{4} .7 \mathrm{H}_{2} \mathrm{O}, 0.02 ; \mathrm{FeCl}_{3}$, trace. The $\mathrm{pH}$ value of the solution was adjusted to $\mathbf{7 \cdot 2}$.

Carbon compounds used. For the oily substances $0.2 \mathrm{ml}$./bottle of each was used. For solid water-insoluble substances, a few flakes of each substance were added to the salt solution in the $2 \mathrm{oz}$. bottles before autoclaving. Fatty acids were used as sodium or potassium salts. Thus the only carbon source, apart from atmospheric $\mathrm{CO}_{2}$, involved in the growth experiments, was the carbon compound added to the salt solution. Whenever possible highly purified chemicals were used.

Inoculum. One or two drops of a thin suspension of Nocardia opaca in distilled water was used to inoculate each culture bottle. This suspension was 
prepared by adding a sufficient amount of organism, obtained from the surface of solid medium, to $5 \mathrm{ml}$. sterile distilled water in a $2 \mathrm{oz}$. screw-capped bottle containing a few glass beads. For this purpose the organism was grown on the medium used by Webley \& de Kock (1952) for 2 days at $25^{\circ}$. As it is difficult to standardize a suspension of a pleomorphic organism by counting methods the final suspension was made so as to give a slight turbidity visible to the naked eye after shaking by hand for $\frac{1}{2}-1$ min. with the glass beads. After inoculation the bottles were incubated at $23-25^{\circ}$ and examined daily. Owing to the physical nature of most of the substrates and the mode of growth of the organism on them it was not possible to assess the amount of growth by conventional methods.

Examination of growth. Examination by microscope was periodically carried out by the ordinary hanging-drop technique; at the same time heat-fixed smears were made for the following staining reactions: (a) Gram's method (Hucker's modification); (b) acid-fast stain (Gordon \& Smith, 1953); (c) fat stain (Burdon, 1946); $(d)$ polysaccharide stain of Hotchkiss as described by Glick (1949). In method $(d)$ the ethanolic periodic acid 'A' solution was used and the counter-stain omitted. The periodic acid solution was allowed to act for $1 \mathrm{hr}$., while the Feulgen reagent (prepared by reduction with $\mathrm{SO}_{2}$ ) was subsequently used for $20 \mathrm{~min}$. The rest of the procedure was as described by Glick (1949).

Preparation of specimens for electron microscope examination. Small drops, obtained by dipping the end of an ordinary platinum inoculation wire down to the oil/aqueous interface in the case of the oils (i.e. the site of growth of the organism), were placed on copper electron microscope specimen grids which had been covered with a thin formvar film. The specimens were fixed in formalin vapour and then dried in a desiccator overnight before mounting in the microscope.

\section{RESULTS}

\section{Growth of Nocardia opaca on saturated aliphatic hydrocarbons}

The organism grew rapidly (2-3 days) on the long chain hydrocarbons $n$-dodecane $\left(\mathrm{C}_{12}\right), n$-tetradecane $\left(\mathrm{C}_{14}\right)$ and $n$-hexadecane $\left(\mathrm{C}_{16}\right)$ and slightly less rapidly on the solid $n$-octadecane. Growth on lower members of the series (heptane, octane, nonane) was poor in comparison. In the case of the $\mathrm{C}_{12}, \mathrm{C}_{14}$, $\mathrm{C}_{16}$ hydrocarbons, which were oils at the temperature used, growth took place at the oil/water interface. $n$-Octadecane is a solid below $\mathbf{2 8}^{\circ}$, and the organism grew first at the solid surface and then settled to the bottom of the tube, although flakes of hydrocarbon might remain floating at the surface. At $30-31^{\circ}$, when $n$-octadecane is liquid, growth took place as for the $\mathrm{C}_{12}, \mathrm{C}_{14}$ and $\mathrm{C}_{16}$ hydrocarbons, the cells sticking firmly to the oil and only depositing after most of the hydrocarbon had been used.

The initial mycelial phase was well developed on the oils (Pl. 1, figs. 1, 2). The cells were acid-fast and had deeper staining Gram-positive granules inside the slender mycelium (Pl. 1, fig. 1). These granules also stained more deeply than the rest of the cell with fat or polysaccharide stains (Pl. 1, figs. 3, 4). Under the electron microscope well-defined granules were seen inside the 
mycelium (Pl. 1, fig. 2). In short elements these granules were usually situated at the poles of the cell ( $\mathrm{Pl}$. 1, fig. 5). Increasing the intensity of the electron beam produced 'vacuolation' of the granules (Pl. 1, fig. 6) in an identical manner to that obtained by Mudd et al. (1951) for Mycobacterium thamnopheos and more recently by Brieger, Cosslett \& Glauert (1954) for strains of $M$. avium.

\section{Growth of Nocardia opaca on saturated aliphatic alcohols}

No growth, or very little, was obtained with the following alcohols: butyl, amyl, hexyl, heptyl, octyl, decyl, undecyl and dodecyl. It was previously found (Webley \& de Kock, 1952) that butyl, amyl, hexyl and heptyl alcohols were inhibitory to the respiration of washed suspensions of the organism. On the other hand, enhanced oxygen uptake was obtained in the presence of decyl and dodecyl alcohols. Growth, however, took place on cetyl alcohol $\left(\mathrm{C}_{16}\right)$ and on stearyl alcohol $\left(\mathrm{C}_{18}\right)$. On the latter compound the initial mycelial phase was short lived and the mycelium quickly fragmented into the short element phase.

\section{Growth of Nocardia opaca on saturated aliphatic fatty acids}

Lower fatty acids $\left(\mathrm{C}_{2}-\mathrm{C}_{7}\right)$. Good growth takes place on acetate, $n$-butyrate, iso-butyrate, $n$-hexanoate and $n$-heptanoate at $0.5 \%(\mathrm{w} / \mathrm{v})$. The development of the initial mycelial phase was not so well marked as with the hydrocarbons; fragmentation tended to take place more quickly. The usual granules which stained with the polysaccharide and fat stains were observed. Higher homologues in this series of acids under similar conditions did not support growth.

Higher fatty acids $\left(\mathrm{C}_{8}-\mathrm{C}_{20}\right)$. By lowering the concentration to $0.001 \mathrm{M}$ growth was obtained on the following straight chain fatty acids: caprylic, capric, myristic, palmitic, stearic and arachidic. The initial mycelial development of the organism with these compounds was short lived (shorter than with the lower fatty acids-see above), and it fragmented into the short element phase (Pl. 1, fig. 7) after 2-3 days. Most of the cells deposited at the bottom of the culture bottles. The growth, which took place at the surface of the culture medium, was composed of highly refractile cells possessing a marked tendency to creep up the sides of the bottle on shaking. Very few cells remained suspended in the liquid medium itself when these fatty acids were used. The cells were acid-fast and Gram-positive, with internal granules which stained in a similar manner to those obtained in the growth on hydrocarbons.

\section{Growth of Nocardia opaca on vegetable oils and waxes}

Vegetable oils. Very good growth (2-3 days) was obtained on the following vegetable oils: olive, almond, castor, rape seed, maize, soya bean, safflower seed, tea seed, ground-nut, cotton seed and cocoa-nut. Growth took place at the oil/water interface in the same manner as that observed with the hydrocarbon oils. The cells and internal granules stained in a similar manner to that described for growth on the hydrocarbons. Webley (1953) showed that a well- 
developed mycelial stage was initially produced by Nocardia salmonicolor when growing on vegetable oils.

Waxes, etc. The following waxy substances were tried: beeswax, sandal leaf wax and synthetic palmitone. Beeswax was the only one of these substances on which the organism grew. On beeswax the cells did not attach themselves so firmly to this solid in the manner observed for oily substances (see also comparative behaviour in $n$-octadecane when in the oil and solid phase). Fragmentation quickly took place into the short element phase and most of the cells settled to the bottom of the culture bottle.

\section{Growth of Nocardia opaca on various surface-active and related substances}

Many surface-active substances possess paraffinic chains in their structures (Glassman, 1948). Bearing this in mind and also the well-known effect of 'Tween $80^{\prime}$ ' on the growth of Mycobacterium tuberculosis (Dubos \& Middlebrook, 1948) it was considered worthwhile to try these compounds as sole carbon source for Nocardia opaca. It was found that while cationic and anionic surface active compounds containing a paraffinic chain did not serve as sole C source for $N$. opaca, Tween 80 , on the other hand, at $0.1 \%$ supported growth of the organism; the sodium salt of cholic acid also gave good growth at a similar concentration. Little growth at the liquid/air surface was obtained with Tween 80 or sodium cholate; the cells quickly settled to the bottom of the culture bottle and were in the short element phase. A similar result was obtained with $0.1 \%$ bile salt as sole carbon source. $N$. opaca grew with cholesterol as sole carbon source; Turfitt (1944) showed that species of Proactinomyces used cholesterol as sole carbon source.

\section{DISCUSSION}

The ability of the partially acid-fast nocardias to grow on liquid or solid paraffins is well known (Jensen, 1931; Erikson, 1949). Erikson (1949) has also shown that the proportion of this type of organism among soil nocardias is quite considerable. Thus out of 300 soil strains she studied $31 \%$ were partially acid-fast. The finding that Nocardia opaca can grow rapidly on vegetable oils and also utilize long chain fatty acids as carbon source indicates that this group of organisms may be of importance in the breakdown of lipid material which takes place in soil.

The reason for the more pronounced development and persistence of the initial mycelial phase on oils (particularly hydrocarbons) may be connected with the rather different physical factors operating at the oil/water interface as compared with those in aqueous solutions and in solid + water systems.

The presence of well-defined granules inside the cells was reported and studied in detail by McClung (1950) who grew the organisms mainly in medium containing glycerol. In the present investigation granules were also observed in the cells of Nocardia opaca. They stained more intensely than the rest of the cell with fat and with polysaccharide stains. Under the electron microscope well-defined dense bodies were seen (Pl. 1, figs. 2, 5) which behaved in 
a similar manner to the 'mitochondria' in Mycobacterium thamnopheos (Mudd et al. 1951) under intense electron bombardment. Whether these bodies are identical with the granules observed by staining reactions (Pl. 1, figs. 3, 4) is not known with certainty. Comparison of their positions in stained preparations and electron micrographs support the view that they are.

The refractility of the cells and internal granules of Nocardia opaca, as of other fat-utilizing partially acid-fast species of Nocardia, is a property that allies this class of organism more closely with the mycobacteria than with the other group of organisms still retained in the genus Nocardia-viz. the nonacid-fast, non-fat utilizing, carbohydrate fermenting species that have only weakly refractile cells with poorly visible granules, e.g. $N$. flava, $N$. citrea, etc. (Erikson, 1954).

I am grateful to Mrs D. Oxford and Dr G. K. Fraser for their continued interest throughout the work. I am indebted to Mr Gard of the University of Aberdeen for taking the electron micrographs and to Miss Irene Taylor for the photomicrographs. I also wish to thank Mr Rae of the United Africa Co. Ltd. for sending me samples of refined and deodorized vegetable oils, Dr S. G. Knight for samples of surface-active agents not obtainable in this country, Dr M. Webb for the purified sample of cholic acid, Messrs Hess Products Ltd., Littleborough, for the long chain fatty acids and to others for gifts of hydrocarbons of high purity. The author is also grateful to Dr A. C. Chibnall, F.R.S., for the gift of sandal leaf wax, and synthetic palmitone.

\section{REFERENCES}

Brieger, E. M., Cosslett, V. E. \& Glauert, A. M. (1954). Reproductive changes in avian tubercle bacilli studied with the electron microscope. J. gen. Microbiol. $10,294$.

Burdon, K. L. (1946). Fatty material in bacteria and fungi revealed by staining dried, fixed slide preparations. J. Bact. 52, 665 .

Dubos, R. J. \& MiddLebrook, G. (1948). The effect of wetting agents on the growth of tubercle bacilli. J.exp. Med. 88, 81.

ErIKson, D. (1949). Differentiation of the vegetative and sporogenous phases of the actinomycetes. 4. The partially acid-fast proactinomycetes. J. gen. Microbiol. 3, 361 .

ErIKson, D. (1954). Factors promoting cell-division in a 'soft' mycelial type of Nocardia: Nocardia turbata n.sp. J. gen. Microbiol. 11, 198.

Glassman, H. N. (1948). Surface active agents and their application in bacteriology. Bact. Rev. 12, 105.

GurcK, D. (1949). Techniques of Histo- and Cytochemistry. New York and London: Interscience Publishers Inc.

Gordon, R. E. \& Smith, M. M. (1953). Rapidly growing acid-fast bacteria. 1. Species descriptions of Mycobacterium phlei Lehmann and Neumann and Mycobacterium smegmatis Lehmann and Neumann. J. Bact. 66, 41.

Jensen, H. L. (1931). Contributions to our knowledge of the Actinomycetales. 11. The definition and sub-division of the genus Actinomyces with a preliminary account of Australian soil actinomycetes. Proc. Linn. Soc. N.S.W. 56, 345.

McClung, N. M. (1950). Morphological studies in the genus Nocardia. II. Cytological studies. J. Bact. 59, 589.

Mudd, S., Winterscheid, L. C., Delamater, E. D. \& Henderson, H. J. (1951). Evidence suggesting that the granules of mycobacteria are mitochondria. J. Bact. $62,459$. 

Journal of General Microbiology, Vol. 11, No. 3
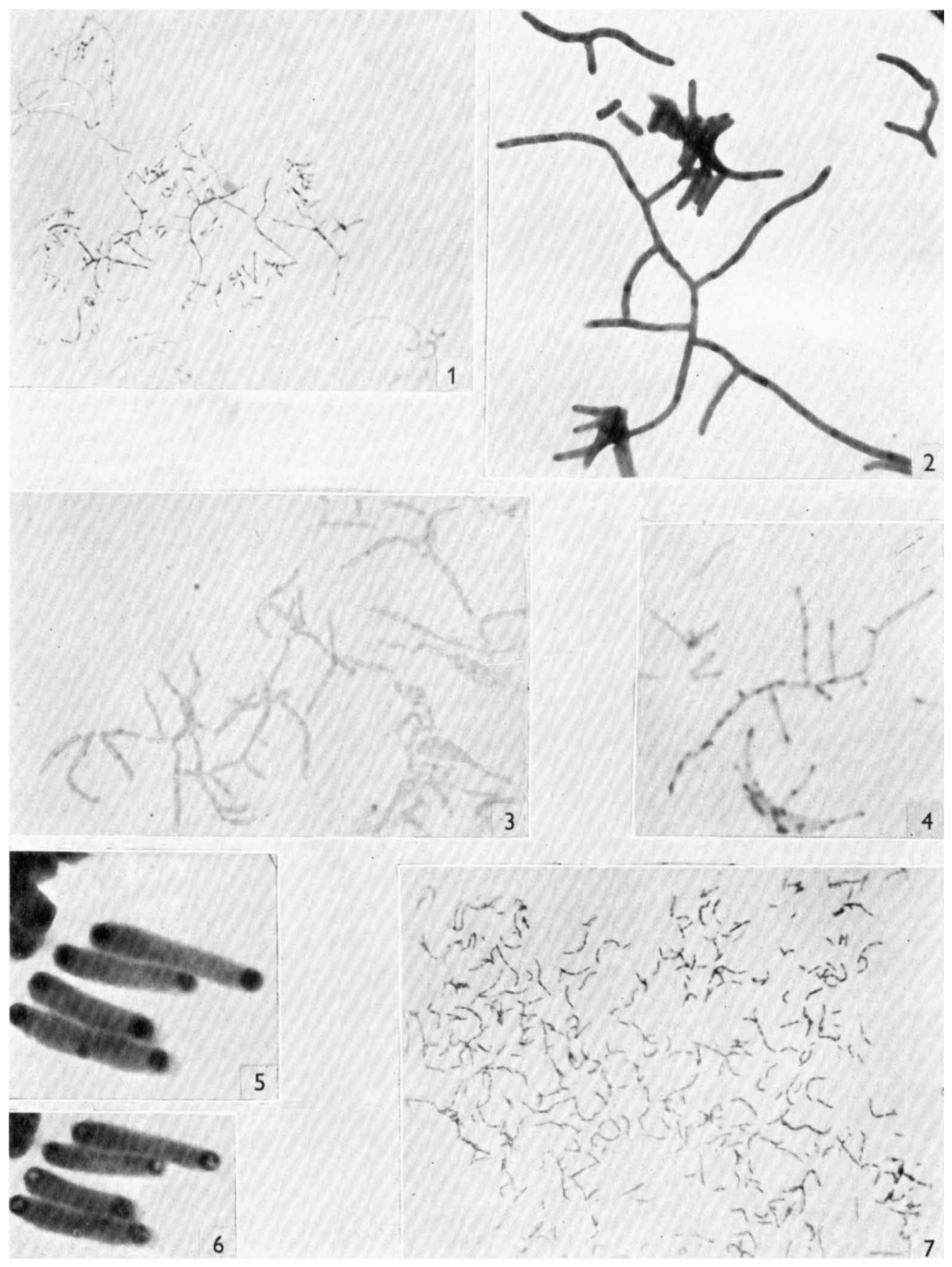

D. M. WEBLLY-Morphology OF NOCARDTA OPACA 
Turfitr, G. E. (1944). The microbiological degradation of steroids. 2. Oxidation of cholesterol by Proactinomyces spp. Biochem. J. 38, 492.

WEBLEY, D. M. (1953). A simple method for producing microcultures in hanging drops with special reference to organisms utilizing oils. J. gen. Microbiol. 8,66 .

Webley, D. M. \& DE Kock, P. C. (1952). The metabolism of some saturated aliphatic hydrocarbons, alcohols and fatty acids by Proactinomyces opacus Jensen (Nocardia opaca Waksman and Henrici). Biochem. J. 51, 371.

\section{EXPLANATION OF PLATE}

Fig. 1. Nocardia opaca grown for 4 days on $n$-dodecane and mineral salts. Gram stain, $\times 960$.

Fig. 2. $N$. opaca grown for 3 days on $n$-dodecane and mineral salts. Electron micrograph, $\times 3700$.

Fig. 3. N. opaca grown for 4 days on $n$-dodecane and mineral salts. Fat stain, $\times 1920$.

Fig. 4. $N$. opaca grown for 2 days on $n$-dodecane and mineral salts. Polysaccharide stain, $\times 1920$.

Fig. 5. $N$. opaca grown for 2 days on $n$-dodecane and mineral salts. Electron micrograph, $\times 12,500$.

Fig. 6. As above after intense electron bombardment. Electron micrograph, $\times 10,000$.

Fig. 7. N. opaca grown for 3 days on 0.001 м-Na palmitate and mineral salts. Gram stain, $\times 960$.

(Received 10 June 1954) 